\title{
FORMAÇÃO DE PROFESSORES A DISTÂNCIA: O QUE PENSAM OS TUTORES?
}

\author{
Marta Fernandes GARCIA ${ }^{1}$ \\ Dirceu da SILVA ${ }^{2}$ \\ Cássio Ricardo Fares RIEDO 3
}

RESUMO: O texto discute os desafios enfrentados por atores educacionais que exercem sua prática pedagógica em ambiente virtual de aprendizagem e problematiza concepções que tutores possuem sobre aspectos da formação a distância. Um questionário foi aplicado em 386 tutores de diferentes regiões do Brasil que trabalham com formação de professores em nível superior a distância. Os resultados mostram que a maioria dos tutores acredita na potencialidade da Educação a Distância $(\mathrm{EaD})$ para uma formação de qualidade, apresenta-se dividida quanto a responsabilidade da tutoria para o sucesso do curso, considera ser mais complexo exercer a docência a distância e evidencia em suas concepções que o mercado de trabalho ainda possui forte preconceito com a EaD.

PALAVRAS-CHAVE: Formação de professores. Educação a distância. Tutor.

\section{Introdução}

A utilização da educação a distância para a formação de professores cresce continuamente no Brasil tanto na esfera privada quanto na pública. Constata-se, por exemplo, pelas iniciativas da Universidade Virtual do Estado de São Paulo (Univesp) e Universidade Aberta do Brasil (UAB), assim como no Plano Nacional de Educação (PNE) 2011-2020, que apresenta em suas estratégias o uso da EaD para atingir metas de ampliação na oferta de vagas no ensino superior e também de cursos de pós-graduação stricto sensu, especialmente por meio da UAB.

Assistimos a um crescimento vertiginoso da modalidade que, em relação ao número de matrículas, avançou de 0,2\% em 2001 para 14,1\%, em 2009. O número de instituições de ensino superior (IES) também apresentou um aumento significativo, saltando de 25 IES em 2002 para 115 em 2008. Os dados ainda evidenciam que metade

\footnotetext{
${ }^{1}$ Doutoranda em Educação. Bolsista do CNPq. Pesquisadora do Laboratório de Inovações Tecnológicas Aplicadas na Educação (LANTEC) e do Grupo de Estudos e Pesquisas em Educação Superior (GEPES). UNICAMP - Universidade Estadual de Campinas. Faculdade de Educação. Campinas - SP - Brasil. 13083-865 - marta_fgarcia@yahoo.com.br

${ }^{2}$ UNICAMP - Universidade Estadual de Campinas. Faculdade de Educação. Campinas - SP - Brasil. 13083-865 - dirceu@unicamp.br

${ }^{3}$ Doutorando em Educação. Bolsista do CNPq. Pesquisador do Grupo de Estudos e Pesquisas em Educação Superior (GEPES) e do Laboratório de Estudos de Educação Superior (LEES). UNICAMP Universidade Estadual de Campinas. Faculdade de Educação. Campinas - SP - Brasil. 13083-865 cfriedo@yahoo.com
} 
dos cursos oferecidos nessa modalidade é de licenciatura, sendo que Pedagogia é o que possui maior número de matrículas e corresponde a $34,2 \%$ dos cursos oferecidos em $\mathrm{EaD}$ (INEP, 2010).

Ao lado desse crescimento em $\mathrm{EaD}$, surgem novos campos profissionais para dar conta do processo formativo em ambiente virtual, entre eles o de tutor. Pesquisadores e especialistas em EaD, como Lapa e Pretto (2010), Belloni (2009), Gatti (2003), Preti (2003) e Pádula ([2002]), discutem os desafios enfrentados pelo tutor e afirmam a importância desse sujeito no processo de formação de professores e demais profissionais, argumentando que a prática desse profissional é decisiva para garantir a qualidade do processo, pois é ele que realiza o trabalho de mediação pedagógica. É desse profissional que se espera a explicação de dúvidas, a condução de discussões, a promoção de atividades e o acompanhamento do processo de aprendizagem. Além disso, como salienta Gatti (2003), o tutor possui também a tarefa de motivar os alunos e de colaborar na construção de laços de afetividade.

No entanto, apesar do relevante papel no processo de ensino e aprendizagem, o tutor tem enfrentado grandes obstáculos na realização de seu trabalho. Geralmente, não foi formado para atuar em $\mathrm{EaD}$ e, desconhecendo a cultura do ambiente virtual, não aprendeu a pensar "com" e "a partir" das tecnologias digitais para realizar intervenções pedagógicas. Além disso, encontra diante de si uma precarização do trabalho docente (LAPA; PRETTO, 2010, FIDALGO; FIDALGO; ARANHA, 2012), o que torna o cenário da educação a distância um desafio ainda maior. Em decorrência dos aspectos apontados e por conta do processo de ensino e aprendizagem ser mais complexo na EaD (MILL, 2010; BELLONI, 2009), interessa-nos refletir sobre as diferentes concepções que tutores do país possuem sobre aspectos da formação a distância, refletindo sobre suas crenças e críticas em relação a essa modalidade. A análise de tais concepções pode ser considerada importante porque, segundo Garnica (2008), são elas que dão suporte para a ação, podendo desencadear práticas significativas, voltadas para questões educativas e centradas na aprendizagem dos alunos, ou mesmo enveredar para práticas tradicionais, de caráter mais tecnicista e administrativo do que pedagógico.

\section{Desafios à prática pedagógica em ambiente virtual de ensino e aprendizagem}

Os impactos das novas tecnologias na prática docente já eram abordados por Kenski (1998), quando apontava a necessidade dos professores e demais atores educativos construírem uma nova lógica, com outros procedimentos didáticos e uma 
nova dinâmica de sala de aula, a qual privilegiasse o trabalho em equipe onde o professor conseguisse passar de mero transmissor do conteúdo para mediador e incentivar da co-construção do conhecimento, concentrando seus esforços para orientálo no processo de aprendizagem. Desta forma, não é recente a discussão sobre as transformações que a prática pedagógica sofre quando desenvolvida em ambientes virtuais de ensino e aprendizagem, apresentando instabilidades aos docentes que se propõem a ensinar usando novas tecnologias. Assim, a transição do presencial para o virtual, na formação de professores, apresenta desafios ao tutor, pois seu local de trabalho não é mais o mesmo, seus alunos geralmente não são crianças ou jovens, o conteúdo a ser desenvolvido exige competências diferenciadas e a forma predominante de comunicação deixa de ser a oral e passa a ser a escrita.

Antes de abordarmos com mais detalhes os desafios postos à docência em ambiente virtual, é preciso responder a uma pergunta: no que consiste a prática pedagógica? Marcelo García (2001), considerando principalmente teorias de "pedagogia ativa", define a prática pedagógica como um conjunto de atividades que permite desenvolver e avaliar processos intencionais de ensino, tendo por objetivo o favorecimento de uma aprendizagem significativa. Para o autor, a tarefa educativa deve estar centrada na aprendizagem e não no conteúdo, além de ser, entre outras características, adaptada às necessidades dos estudantes; ativa por parte dos alunos; autônoma para que se possa aprender a aprender; preocupada com processos colaborativos e centrada em problemas. Neste mesmo sentido, Cordeiro (2011, p.66) esclarece que o trabalho pedagógico é "um tipo de atividade que se exerce na presença dos outros e em função desses outros, os alunos" e que a relação pedagógica deve ser intencional, buscando garantir o acesso a um conjunto de saberes, além de englobar de modo positivo a relação entre professor, aluno e conhecimento. A essência da prática pedagógica na $\mathrm{EaD}$ não é diferente, porém é ampliada na medida em que requer o conhecimento de novos modelos pedagógicos especificamente apropriados a $\mathrm{EaD}^{4}, \mathrm{e}$ embasados em paradigmas e teorias educacionais de aprendizagem focados na educação a distância (BEHAR, 2009).

Assim, torna-se importante questionar os desafios postos na formação a distância

4 Behar (2009, p.24) define modelo pedagógico para EaD como “[...] um sistema de premissas teóricas que representa, explica e orienta a forma como se aborda o currículo e que se concretiza nas práticas pedagógicas e nas interações professor/aluno/objeto de estudo. Nesse triângulo (professor, aluno e objeto) são estabelecidas relações sociais em que os sujeitos irão agir de acordo com o modelo definido." A autora apresenta e discute em seu texto os elementos de um modelo pedagógico voltado para EaD. 
para a efetivação do processo de ensino e aprendizagem com qualidade a qualidade desejada. Lapa e Pretto (2010) apontam que o professor que atua na EAD encontra outros desafios além daqueles já existentes no ensino tradicional e descreve quatro deles. O primeiro está relacionado com o afastamento temporal entre a elaboração do material e a prática pedagógica, pois geralmente os professores autores dos materiais não são os responsáveis pela mediação. Além disso, nos materiais estão presentes as concepções e crenças do professor autor e não necessariamente do tutor, cabendo a este fazer o esforço de se apropriar de uma proposta pedagógica elaborada por outro profissional.

O segundo desafio se refere ao distanciamento espacial. Para Lapa e Pretto (2010), é preciso que os professores tenham a capacidade de construir vínculos e manterem, por meio da utilização das tecnologias, a presença no ambiente virtual. Esse é um grande desafio em decorrência da cultura tradicional presente nas salas de aula, as quais são marcadas pela oralidade e pelo "olho no olho" e, passar a lidar com situações virtuais, como responder por escrito dúvidas do aluno, interagir satisfatoriamente e gerenciar discussões em fóruns, é tarefa complexa, com as quais os professores não estão acostumados.

Ainda sobre a difícil transição da sala de aula tradicional para os ambientes virtuais de aprendizagem, é preciso diferenciar as relações síncronas (que ocorrem ao mesmo tempo) e assíncronas (que ocorrem em determinado intervalo de tempo,). Kenski (2008, p.67, grifo do autor) especifica como um grande desafio "[...] a criação da sensação da presença síncrona em um espaço em que dificilmente os alunos estão presentes no mesmo momento.” Essa sensação da presença síncrona, como se todos estivessem sempre presentes, pode contribuir significativamente para a "convivência digital virtual em rede" (SCHLEMMER, 2010). Para Giolo (2008), a prática da experimentação, da convivência, dos debates e conversas não se realiza completamente por relações instrumentalmente mediadas, pois os seres humanos necessitam, como uma característica social, da presença do outro. Em função disso, o autor argumenta a favor da oferta de cursos a distância com encontros de formação presenciais regulares, para além do momento singular e isolado de aplicação de prova presencial, presente em alguns modelos de formação. Contudo, apesar da argumentação do autor, não foram encontrados estudos científicos que indiquem que as relações assíncronas não possam suprimir até um determinado limite a necessidade de interações sociais, mas ressaltam que as interações devem ir muito além das provas presenciais. 
O terceiro desafio apontado por Lapa e Pretto (2010, p. 84) "vem da explosão do papel do professor". Aqui, entra em cena a complexa questão dos sujeitos e seus papéis no ambiente virtual. Para os autores, todos contribuem para o papel docente, apesar de cada um ter um papel diferente, pois apenas um sujeito não daria conta de todas as tarefas educativas necessárias para uma formação de qualidade online. Belloni (2009) também aponta essa diversidade de sujeitos que trabalham na EAD e argumenta que todos colaboram no processo de ensino-aprendizagem a distância, mas que é fundamentalmente do tutor a tarefa de orientar e contribuir com a aprendizagem do aluno.

O último desafio apresentado diz respeito ao deslocamento da centralidade do ensino do professor para a aprendizagem do aluno, o que implica a superação de práticas tradicionais em que o professor é o centro do processo e único detentor do conhecimento. O desafio está na dificuldade de mudança da cultura escolar, a qual tradicionalmente preparou o aluno para a passividade e o professor para ser o detentor dos saberes. Convém ressaltar que, normalmente diante de situações inusitadas e dinâmicas, os professores reproduzem as práticas com as quais tiveram contato ao longo da vida, seja na condição de aluno ou de professor (GARCIA et al., 2011). O conceito de simetria invertida (MELLO, 2000) nos ajuda a compreender melhor a reprodução de práticas tradicionais na educação a distância, evidenciando que a experiência enquanto aluno é parte constitutiva da prática futura como professor. Modelos didáticos, atitudes e modos de organização vivenciados enquanto alunos se refletirão na vivência do futuro profissional, sendo desejável desenvolver, numa situação invertida enquanto aluno, o que será esperado ao exercer a docência. Portanto, considerando o conceito da simetria invertida, surgem as indagações: por quais experiências de formação passaram os sujeitos que atuam como tutores? Tal formação os preparou para uma situação de uso crítico das TIC? Foram contemplados estudos específicos sobre EaD, formação de adultos e comunicação em ambiente virtual? Além do exposto, quando se trata de formação de professores em serviço, o desafio é ainda maior, pois, como enfatizam Alonso e Alegretti (2003), não se trata de pessoas iniciando uma aprendizagem qualquer, mas de adultos com experiência profissional, com atitudes e hábitos consolidados que lhe dão segurança e confiança no próprio trabalho. Considerando a formação continuada, torna-se importante refletir ainda se os tutores foram preparados para dar conta de desequilibrar estruturas cognitivas, conceitos, crenças e atitudes já consolidados em estudantes-professores experientes no magistério. Schlemmer (2010) 
também apresenta questionamentos neste sentido e afirma a importância do professor que trabalha na $\mathrm{EaD}$ vivenciar processos de formação e capacitação em ambiente virtual, pois a experiência como aluno o ajudaria a sentir e refletir com maior contextualização sobre o processo de aprendizagem nesta modalidade de ensino.

O gerenciamento do tempo para evitar a sobrecarga de trabalho em decorrência do tempo de interação com os alunos também pode ser considerado um grande desafio presente na prática do tutor segundo Palloff e Pratt (2004). Devido ao fato do curso permanecer aberto todos os dias da semana e da possibilidade dos alunos postarem mensagens em modo assíncrono, isto é, não simultaneamente, pode-se acumular um grande volume de mensagens a ser lido, o que exigirá do tutor estratégias para evitar a sobrecarga. Segundo os autores, é preciso saber lidar com a ansiedade gerada pelo volume de informações e organizar o tempo para que tanto o tutor quanto os alunos tenham momentos de distanciamento das atividades.

Sobre o aumento da carga de trabalho do tutor, Valverde Berrocoso e Garrido Arroyo (2005) apresentam uma consideração importante ao observar que o tempo necessário para desenvolver intervenções educativas no ambiente virtual é três vezes maior que o empregado em uma aula presencial. As autoras consideram que é necessário, pelo menos uma vez ao dia, acessar o ambiente e responder às questões dos alunos, dar avisos e se fazer presente. Gaytan e McEwen (2007) também apontam a complexidade do trabalho na modalidade a distância, pois o tutor, diferente do professor na modalidade presencial, acompanha os mesmos alunos por muito mais tempo, ou seja, ao longo de todo o curso.

Dentre os desafios, também está presente a mudança na forma de comunicação. Diferentemente do ensino presencial, que faz uso intenso da oralidade, no ambiente virtual a forma de comunicação predominante passa a ser a escrita, o que exige maior competência discursiva. Marcuschi (2004, p. 47) enfatiza que: “[...] a passagem da fala para a escrita não é a passagem do caos para a ordem: é a passagem de uma ordem para outra ordem." Torna-se necessário, portanto, que o tutor conheça bem essas duas ordens e que saiba contextualizar o seu discurso, produzindo enunciados coerentes com as ferramentas tecnológicas utilizadas e com as necessidades do momento de produção.

Assim, os sujeitos que habitam o espaço virtual encontram pela frente o desafio de organizar sua mensagem por escrito para se fazer entender, além do esforço de compreender os seus interlocutores, superando possíveis falhas e desencontros na comunicação Os tutores precisam encontrar formas que superem a carência do contato 
físico, da voz, da presença do outro, da gestualidade que sempre fizeram parte da cultura da sala de aula presencial, o que implica pensar em diferentes elementos, em formatos diversificados, em novas formas de utilização do espaço gráfico e em diferentes modos de organização do discurso para tornar mais compreensível aquilo que deseja comunicar. O esforço e a necessidade de escrever constantemente é um desafio que também apresenta benefícios, pois tudo o que se discute permanece registrado no ambiente virtual, o que possibilita momentos de pausa, de reflexão e de retorno ao conteúdo quantas vezes for necessário (HALABAN, 2010).

No contexto online também é fundamental pensar o número de alunos por turma, pois, considerando apenas a relação entre tutor e alunos, Palloff e Pratt (2004) apontam que este fator pode comprometer a qualidade da formação. É interessante para as instituições, principalmente as privadas, ter um grande número de alunos. Entretanto, se o grupo for muito grande, os tutores terão significativa dificuldade em responder e interagir satisfatoriamente com os alunos que poderão se sentir sozinhos e perdidos entre as tarefas e discussões. Contudo, é preciso levar em consideração o fato de que também se espera uma satisfatória interação entre os alunos na $\mathrm{EaD}$, o que facilitaria o trabalho de intervenção a ser realizado pelo tutor diante de um grande número de estudantes, permitindo que estes também exerçam o papel de mediador. A tutoria pode contar também com ferramentas de indicação de percursos e contribuições, o que auxilia na indicação da necessidade de realização das intervenções.

Esperamos que os desafios aqui levantados possam servir como objeto de análise e reflexão com vista à política de formação de tutores que encontram o grande desafio de ressignificar seu papel na prática pedagógica a distância. Contudo, Lapa e Pretto (2010) esclarecem que é insuficiente o tutor compreender e aceitar tal desafio, e buscar transformar sua prática, se não for dado a ele condições objetivas e oportunidades para viabilizar as transformações desejadas e presentes nos discursos científicos.

\section{A pesquisa e o perfil dos participantes}

Um questionário online foi aplicado no primeiro semestre de 2013 em tutores de diferentes instituições de ensino superior do Brasil para avaliar suas concepções sobre aspectos da formação a distância. Dos 472 tutores que participaram da pesquisa, 386 responderam completamente o questionário. Assim, os questionários incompletos não foram considerados na realização das análises, sendo 386 o universo analisado de respondentes. 
Os sujeitos responderam a 13 questões disponibilizadas por meio de uma escala do tipo Likert com cinco níveis de resposta. Assim, os respondentes manifestaram seu grau de concordância sobre as assertivas apresentadas, escolhendo entre as opções: (1) discordo totalmente; (2) discordo; (3) indiferente; (4) concordo, e (5) concordo totalmente.

Os dados obtidos foram submetidos à análise de frequência de alternativa de respostas e a cruzamento de dados, utilizando-se para esta finalidade o software Statistical Package for Social Sciences (SPSS) versão 15.0. A seguir, apresentamos a análise descritiva do perfil dos participantes. A maior parte dos sujeitos $(67,6 \%)$ é do sexo feminino e se declarou como casado (58\%), seguido de solteiro $(25,4 \%)$, separado $(14,8 \%)$ e viúvo $(1,8 \%)$. Em relação à faixa etária, a tabela 1 apresenta a distribuição dos respondentes e mostra que a grande concentração está entre 31 e 50 anos.

Tabela 1 - Faixa etária

\begin{tabular}{|c|c|c|c|c|c|}
\hline Faixa etária & $\mathbf{2 0}$ a 30 & $\mathbf{3 1}$ a 40 & $\mathbf{4 1}$ a 50 & $\mathbf{5 1}$ a 60 & Mais de 60 \\
\hline$\%$ & 14,2 & 31,9 & 30,6 & 17,6 & 5,7 \\
\hline
\end{tabular}

Fonte: Elaboração própria com dados da pesquisa.

Um pouco mais da metade dos sujeitos é formado em instituições públicas de ensino superior $(52,3 \%)$ e, quanto aos cursos em que são formados, a maior parte provêm das licenciaturas, sendo o de Pedagogia o que apresenta maior porcentagem $(39,1 \%)$, seguido de Letras $(10,1 \%)$, Biologia (4,7\%), Sociologia $(3,4 \%)$, História $(3,1 \%)$, Matemática (2,3\%), Geografia (2,1\%), Filosofia e Artes (1,3\% cada), Física $(0,8 \%)$ e Educação Física $(0,5 \%)$. A formação no bacharelado na área das exatas representa $19,5 \%$ e das biológicas, $12,5 \%$.

Os cursos em que atuam são, na maior parte, Pedagogia (44,3\%), Letras $(9,6 \%)$, Biologia (2,8\%), História (1\%), Física $(0,8 \%)$ e Artes Visuais (1,6\%). Mais da metade declarou trabalhar em instituições públicas de ensino superior $(56,7 \%)$. Suas instituições estão localizadas no Estado de São Paulo (51,8\%), Rio de Janeiro (15\%) e Distrito Federal (6,5\%), Paraíba (3,6\%), Minas Gerais (3,4\%), Mato Grasso do Sul (2,8\%) e Rio Grande do Sul (2,8\%), Paraná (2,3\%), Espírito Santo (2,1\%), Ceará (1,6\%), Pernambuco (1,3\%), Bahia (1\%), Goiás, Tocantins e Roraima (0,8\% cada), Alagoas, Amapá, Mato Grosso e Santa Catarina (0,5\% cada) e, com 0,3\%, estão os estados da Amazônia, Pará, Piauí, Rio Grande do Norte e Sergipe. 
A tabela 2 apresenta o grau de escolaridade dos professores tutores participantes da pesquisa.

Tabela 2 - Nível de Escolaridade

\begin{tabular}{|c|c|c|c|c|}
\hline Nível & Graduação & Especialização & Mestrado & Doutorado \\
\hline$\%$ & 6 & 50,8 & 36,5 & 6,7 \\
\hline
\end{tabular}

Fonte: Elaboração própria com dados da pesquisa.

A especialização é o maior grau para 50,8\% dos sujeitos. Esse dado é relevante principalmente quando levamos em consideração que a escolaridade dos sujeitos não está, em larga escala, de acordo com o disposto no art. 66 da LDB que garante: “A preparação para o exercício do magistério superior far-se-á em nível de pós-graduação, prioritariamente em programas de mestrado e doutorado." (BRASIL, 1996, p.23). Partindo dessa constatação, pode-se pensar no pouco interesse daqueles que tem maior escolaridade em trabalhar com $\mathrm{EaD}$, por conta do preconceito ainda existe em relação a modalidade ou em decorrência da precarização do trabalho, ou no grande interesse das instituições privadas em contratar os que possuem menor escolaridade para reduzir custos.

As tabelas 3 e 4 apresentam, respectivamente, o tempo de atuação no ensino e o tempo de trabalho como tutor. Percebemos que a experiência dos sujeitos no ensino é grande, mas na educação a distância a maior parte fica em até 5 anos, o que é facilmente explicável devido à recente evolução da $\mathrm{EaD}$.

Tabela 4 - Tempo de atuação no ensino

\begin{tabular}{|c|c|c|c|c|}
\hline Até 1 Ano & 2 a 5 Anos & $\mathbf{5}$ a 10 Anos & $\mathbf{1 0}$ a 20 Anos & Mais de 20 Anos \\
\hline $3,9 \%$ & $23,1 \%$ & $24,1 \%$ & $23,3 \%$ & $25,6 \%$ \\
\hline
\end{tabular}

Fonte: Elaboração própria com dados da pesquisa.

Tabela 3 - Tempo de atuação como professor tutor

\begin{tabular}{|c|c|c|c|c|}
\hline Até 6 meses & $\mathbf{1}$ a 3 Anos & $\mathbf{3}$ a 5 Anos & $\mathbf{5}$ a 10 Anos & Mais de 10 Anos \\
\hline $6,7 \%$ & $39,4 \%$ & $32,6 \%$ & $18,7 \%$ & $2,6 \%$ \\
\hline
\end{tabular}

Fonte: Elaboração própria com dados da pesquisa. 
Um dado relevante a ser observado no perfil é que $80,8 \%$ dos sujeitos declararam que o emprego de professor tutor não é o principal e $87 \%$ afirmaram ter outro emprego além do de tutor. Desses, $89,4 \%$ informaram que o outro emprego é presencial. Essas informações dialogam com as afirmações postas por Fidalgo, Fidalgo e Aranha (2012) e Lapa e Pretto (2010) sobre a precarização do trabalho docente na $\mathrm{EaD}$, em que o tutor é contratado em regime precário, com uma jornada de trabalho exaustiva e com baixos salários para desempenhar o papel de professor. Da mesma forma, a precarização do trabalho docente também está presente no ensino presencial, principalmente quando consideramos a privatização do ensino superior no país, em que muitos professores são contratados como autônomos ou por contrato temporário de trabalho e encontra, em muitas instituições de ensino superior, escassos materiais e baixa infraestrutura, além do pouco investimento em iniciativas de pesquisas docentes.

\section{Concepções dos professores tutores sobre formação de professores a distância: resultados e discussão}

Concepções são crenças, percepções, juízos e experiências prévias a partir dos quais nos julgamos aptos a agir. Estudar concepções significa adentrar num meio extremamente dinâmico e inconstante, pois as concepções não são estáveis; ao contrário, estão em constante transformação, ainda que existam algumas zonas de estabilidade (GARNICA, 2008). Assim, nosso interesse em investigar as concepções de tutores deve-se à relevância que possuem para o desenvolvimento da prática de tutoria, na medida em que se tornam suporte para a ação pedagógica. A seguir, apresentamos os dados e analisamos os resultados de cada questão referente às concepções que os sujeitos apresentam sobre aspectos relacionados à formação a distância.

A grande maioria dos tutores $(73,05 \%)$ acredita que ser professor na modalidade a distância é mais complexo que na modalidade presencial. Esse dado vai ao encontro do disposto na literatura que afirma que o trabalho docente na $\mathrm{EaD}$ é organizado dentro de uma rotina e organização diferentes e que é mais intensamente fragmentado do que no ensino presencial, sendo realizado por diferentes sujeitos de diferentes campos, tornando-se, assim, ainda mais complexo que o ensino presencial (MILL, 2010). Além disso, é preciso levar em consideração que o tempo empregado em intervenções educativas no ambiente virtual é três vezes maior que em uma aula presencial (VALVERDE BERROCOSO; GARRIDO ARROYO, 2005). 
Quando questionados sobre a tarefa de avaliação, 63,69\% afirmaram que na $\mathrm{EaD}$ é mais difícil realizar a avaliação devido ao grande número de alunos e 37,56\% afirmaram que na EaD é mais difícil realizar a avaliação devido ao grande número de tarefas. É importante perceber que a quantidade de alunos em uma turma de graduação de $\mathrm{EaD}$ pode interferir na qualidade do processo avaliativo, entendendo este como contínuo e formativo e, consequentemente, na aprendizagem dos alunos, pois os tutores poderão apresentar significativa dificuldade para interagir satisfatoriamente com os alunos no tempo necessário para realização da avaliação, comprometendo os feedbacks. Com esta preocupação, alguns pesquisadores sugerem que professores que trabalham no ensino online devem ter até 25 alunos (PALLOFF; PRATT, 2004).

Sobre a relevância do trabalho de tutoria, é interessante observar que 52,84\% dos sujeitos consideram que o tutor é o maior responsável pelo sucesso do curso. E, $86 \%$ afirmaram que o tutor é o grande responsável pela qualidade da interação entre os alunos. Por um lado, os sujeitos apresentam-se divididos quanto à responsabilidade da tutoria para o sucesso do curso, deixando claro que outros aspectos, como proposta pedagógica, escolha do ambiente virtual e conteúdos, devem ser levados em consideração quando se trata de apontar os maiores responsáveis pelo sucesso de um curso. Por outro lado, suas concepções evidenciam que boa parte dos sujeitos se sente responsabilizado em manter a qualidade da interação entre os alunos. Acreditamos que o diálogo entre os alunos é fundamental e, às vezes, a discussão pode ser desviada da questão central a ser debatida, o que exigiria a intervenção do tutor para a retomada do foco. Assim, o profissional tutor possui, inegavelmente, uma função pedagógica e é essencialmente ele que precisa dar conta da difícil tarefa de levar o aluno a aprender e a interagir no ambiente virtual (BELLONI, 2009).

Em relação aos materiais instrucionais, que constituem parte importante dos cursos em EaD (NEDER, 2009), os dados mostram que os sujeitos apresentam diferentes concepções sobre sua relevância na formação. Diante da assertiva: "Acredito que os materiais instrucionais são suficientes para promover uma excelente aprendizagem”, 6,21\% discordaram totalmente, 45,33\% discordaram da afirmação, $5,44 \%$ concordaram totalmente, $34,97 \%$ concordaram e $8,03 \%$ foram indiferentes. No material didático estão contidos os conceitos e as reflexões fundamentais para as construções de significados que se desejam produzir no desenvolvimento do currículo. É o material didático “[...] que possibilita que as diretrizes e os princípios definidos no projeto político pedagógico do curso sejam garantidos no desenvolvimento da prática 
pedagógica.” (NEDER, 2009, p.81). O material didático (apostilas, livros, cadernos de formação, vídeos etc.) carrega as concepções de educação, de homem, de avaliação, de projeto de profissional daqueles que os produziram e, por esta razão, pode conduzir a diferentes processos formativos. Posto isso, e diante do fato de que não é a tutoria que elabora, geralmente, o material instrucional, fica evidente a necessidade de formação adequada do tutor para a realização de intervenções pedagógicas e críticas junto aos alunos quando julgar que os materiais não estão a favor de uma formação emancipatória, reflexiva e centrada nos alunos.

Os sujeitos discordaram fortemente $(92 \%)$ que a $\mathrm{EaD}$ é procurada somente por pessoas que desejam se diplomar facilmente ou por aquelas que não podem cursar o ensino presencial $(77,7 \%)$, concepções que muitos ainda possuem devido a não exigência da presença diária nas instituições de ensino. Os sujeitos também acreditam que fazer um curso na modalidade a distância não é mais fácil do que fazer um curso presencial (85\%), que os alunos têm as mesmas condições de aprender tanto no ensino presencial quanto na educação a distância $(78 \%)$ e que a falta de contato físico diário não prejudica a aprendizagem dos alunos $(68,9 \%)$. A questão da necessidade de encontros presenciais e a sua quantidade é uma questão importante a ser pensada na educação a distância. Para Giolo (2008), a prática da experimentação, da convivência, dos debates e conversas não se realiza completamente por relações instrumentalmente mediadas, pois os seres humanos necessitam da presença do outro. Em função disso, argumenta a favor da oferta de cursos a distância com encontros de formação presenciais regulares (formato semipresencial). Acreditamos que cursos longos, como é o caso de uma graduação, devem conter em sua organização encontros presenciais regulares de formação, pois estes podem contribuir significativamente para aumentar o envolvimento com o curso, o sentimento de pertencimento à instituição e a motivação dos alunos.

É interessante observar que a maior parte dos professores tutores (58\%) não acredita que o profissional formado a distância é tão bem aceito pelo mercado de trabalho quanto o profissional formado pelo ensino presencial, evidenciando que há a crença social de que os formados nesta modalidade de ensino enfrentarão preconceitos no mercado de trabalho. O preconceito, contudo, está dentro da própria universidade, principalmente das públicas, que considera a modalidade a distância, muitas vezes, como uma forma de aligeirar e baratear o processo formativo (FREITAS, 2007), esquecendo-se das suas potencialidade e possibilidades. Essa é uma questão polêmica e 
uma investigação posterior mais aprofundada nesse sentido poderá ajudar a compreender com maior clareza as razões ainda existentes para esse preconceito em relação à qualidade da formação a distância.

Um último questionamento revelou que a maioria dos tutores participantes da pesquisa $(70,2 \%)$ afirmou não se sentir desvalorizada ao relatar para alguém que trabalha com $\mathrm{EaD}$, demonstrando que considera o trabalho com formação de professores na modalidade a distância tão importante quanto na modalidade presencial, pois em ambas está presente a responsabilidade de educar sujeitos em processo de formação. No entanto, um número considerável $(29,8 \%)$ demonstrou possuir esse sentimento de desvalorização e um cruzamento de dados realizado no SPSS revelou que esses sujeitos são, principalmente, aqueles que possuem como grau máximo de escolaridade o mestrado e o doutorado, ou seja, os que possuem maior grau de escolaridade manifestaram maior descontentamento, que pode estar mais relacionado às condições de trabalho e menos relacionado com a EaD, enquanto modalidade.

\section{Considerações finais}

Analisar as concepções de tutores pode contribuir significativamente para (re) pensar o processo formativo a distância. Levar em consideração os aspectos apontados pelos sujeitos que atuam diretamente com a formação de professores pode colaborar para melhor qualificar a EaD.

Sabemos que a qualidade da atuação dos tutores deve-se, em parte, à sua formação. Tutores bem formados, com conhecimentos sólidos sobre $\mathrm{EaD}$, processos de ensino e aprendizagem, avaliação e a utilização de tecnologias digitais e formas de comunicação no ambiente virtual, em condições de realizar boas práticas, colaborarão de modo mais significativo para a aprendizagem dos alunos. Assim, além do cuidado no recrutamento desses profissionais, atentando para suas experiências e formação, é necessária uma formação contínua que vise o seu desenvolvimento profissional. As tecnologias digitais e os diferentes ambientes virtuais, cada qual com suas especificidades, constituem uma nova cultura educacional para a qual professores e alunos não se encontram, necessariamente, preparados para enfrentar (KENSKI, 1998; PALLOFF; PRATT, 2004; MOORE; KEARSLEY, 2008; BELLONI, 2009; LAPA; PRETTO, 2010; SCHLEMMER, 2010). Trata-se, na verdade, de constatar a crise do paradigma tradicional, que não possui respostas para estes novos modos de participar no processo educacional. 
Apesar dos problemas enfrentados em relação à precarização do trabalho docente, presentes em ambas as modalidades, e de algumas contradições presentes em suas concepções, os tutores apontaram claramente a possibilidade de formação de qualidade da $\mathrm{EaD}$, revelando a crença na potencialidade dessa modalidade de ensino e no trabalho desenvolvido pelos diferentes atores em ambientes virtuais. Acreditar na $\mathrm{EaD}$ é um aspecto fundamental para desenvolver uma prática significativa, transformadora e comprometida com o sucesso dos alunos nas aprendizagens.

\title{
DISTANCE TEACHER EDUCATION: WHAT THINK THE TUTORS?
}

\begin{abstract}
This paper discusses the challenges faced by educational actors performing their practice in virtual learning environment and discusses concepts that teachers have tutors on aspects of distance education. A questionnaire was administered to 386 tutors from different regions of Brazil working with teacher education in higher education level. The results show that most tutors believe in the potential of distance education to quality education, presents itself divided on the responsibility of mentoring for the success of the course, considered to be more complex to be a teacher in distance education and evidence in their conceptions also showed that there is still strong prejudice against distance learning in the labor market.
\end{abstract}

KEYWORDS: Teacher training. Distance learning. Tutor.

\section{REFERENCIAS}

ALONSO, M.; ALEGRETTI, S. M. Introduzindo a pesquisa na formação de professor a distância. In: ALMEIDA, M. E. B. et al. (Org.). Educação a distância via internet. São Paulo: Avercamp, 2003. p.163-174.

BEHAR, P. A. (Org.). Modelos pedagógicos em educação a distância. Porto Alegre: Artmed, 2009.

BELLONI, M. L. Educação a distância. Campinas: Autores Associados, 2009.

BRASIL. Lei no 9.394, de 20 de dezembro de 1996. Estabelece as Diretrizes e Bases da Educação Nacional. Diário Oficial da União, Brasília, 23 dez. 1996.

CORDEIRO, J. A relação pedagógica. In: UNIVERSIDADE ESTADUAL PAULISTA. Caderno de formação: formação de professores didática geral. São Paulo: Cultura Acadêmica, 2011. p.66-79, v.9.

FIDALGO, N. L. R.; FIDALGO, F. ARANHA, A. V. S. Tecnologia e os "novos" desafios para o trabalho docente. In: FIDALDO, F. et al. (Org.). Educação a distância: tão longe, tão perto. Belo Horizonte: Ed. da UFMG, 2012. p.33-51. 
FREITAS, H. C. L. A (nova) política de formação de professores: a prioridade postergada. Educação e Sociedade, Campinas, v.28, n.100, p.1203-1230, out. 2007. Disponível em: <http://www.scielo.br/pdf/es/v28n100/a2628100.pdf>. Acesso em: 07 fev. 2014.

GARCIA, M. F. et al. Novas competências docentes frente às tecnologias digitais interativas. Teoria e Prática da Educação, Campinas, v.14, n.1, p.79-87, jan./abr. 2011. Disponível em: <http://www.dtp.uem.br/rtpe/volumes/v14n1/07.pdf>. Acesso em: 02 abr. 2014.

GARNICA, A. V. M. Um ensaio sobre as concepções de professores de matemática: possibilidades metodológicas e um exercício de pesquisa. Educação e Pesquisa, São Paulo, v.34, n.3. p.495-510, set./dez. 2008.

GATTI, B. Formação continuada de professores: a questão psicossocial. Cadernos de Pesquisa, São Paulo, n. 119, p. 191-204, jul 2003.

GAYTAN, J.; MCEWEN, B. C. Effective online instructional and assessment strategies. The American Journal of Distance Education, [S.1.], v.21, n.3, p.117-132, 2007.

GIOLO, J. A educação a distância e a formação de professores. Educação e Sociedade, Campinas, v.29, n.105, p.1211-1234, set./dez. 2008. Disponível em:

<http://www.scielo.br/pdf/es/v29n105/v29n105a13.pdf>. Acesso em: 07 nov. 2013.

HALABAN, P. La comunicación virtual en educación a distancia: un estudio sobre interacciones comunicacionales y procesos pedagógicos en internet. Buenos Aires: Fundación Centro de Integración, Comunicación, Cultura y Sociedad, 2010.

INSTITUTO NACIONAL DE ESTUDOS E PESQUISAS [INEP]. Censo da educação superior. Brasília, 2010.

KENSKI, V. M. Tecnologias e ensino presencial e a distância. São Paulo: Papirus, 2008.

Novas tecnologias: o redimensionamento do espaço e do tempo e os impactos no trabalho docente. Revista Brasileira de Educação, Rio de Janeiro, n.08, maio-ago, 1998. Disponível em: <http://educa.fcc.org.br/pdf/rbedu/n08/n08a06.pdf>. Acesso em: 25 abr. 2013.

LAPA, A.; PRETTO, N. L. Educação a distância e precarização do trabalho docente. Em Aberto, Brasília, v.23, n.84, p.79-97, nov.2010.

MARCELO GARCÍA, C. Rediseño de la práctica pedagógica: factores, condiciones y procesos de cambio en los teleformadores. In: CONFERENCIA IMPARTIDA EN LA REUNIÓN TÉCNICA INTERNACIONAL SOBRE EL USO DE TECNOLOGÍAS DE LA INFORMACIÓN EN EL NIVEL DE FORMACIÓN SUPERIOR AVANZADA, 2001, Sevilla. Actas... Sevilla: Universidad de Sevilla, 2001. Disponível em: <http://prometeo.us.es/idea/miembros/01-carlos-marcelogarcia/archivos/practica pedagogica.htm> . Acesso em: 18 dez. 2013. 
MARCUSCHI, L. A. Da fala para a escrita: atividades de retextualização. São Paulo: Cortez, 2004.

MELLO, G. N. Formação Inicial de Professores para a educação básica: uma (re) visão radical, 2000. São Paulo em Perspectiva, São Paulo, v.14, n.1, p.98-110, 2000.

Disponível em: <http://www.scielo.br/pdf/spp/v14n1/9807.pdf〉. Acesso em: $11 \mathrm{dez}$. 2013.

MILL, D. Sobre o conceito de polidocência ou sobre a natureza de trabalho pedagógico na educação a distância. In: MILL, D.; OLIVEIRA, M. R. G.; RIBEIRO, L. R. C. (Org.). Polidocência na educação a distância: múltiplos enfoques. São Carlos: EDUFSCar, 2010. p.23-40.

MOORE, M.; KEARSLEY, G. Educação a distância: uma visão integrada. São Paulo: Cengage Learning, 2008.

NEDER, M. L. C. O texto como elemento de mediação entre os sujeitos da ação educativa. In: POSSARI, L. H. V.; NEDER, M. L. C. Material didático para a EaD: processo de produção. Cuiabá: Ed. da UFMT, 2009. p.81-90.

PÁDULA, J. E. Contigo em la distância: el rol del tutor en la educación no presencial. [2002]. Disponível em: <http://www.uned.es/catedraunescoead/publicued/pbc08/rol_bened.htm>. Acesso em: 09 jan. 2014.

PALLOFF, R.; PRATT, K. O aluno virtual: um guia para trabalhar com estudantes. on-line. Porto Alegre: Artmed, 2004.

PRETI, O. O estado da arte sobre "tutoria": modelos e teorias em construção. In: O sistema de orientação acadêmica no curso de pedagogia a distância da

Universidade Federal de Mato Grosso. 2003. Relatório de Pesquisa - Programa CAERENAD, Universidade Federal de Mato Grosso, 2003. Cap.1.

SCHLEMMER, E. Formação de professores na modalidade online: experiências e reflexões sobre a criação de espaços de convivências digitais virtuais. Em Aberto, Brasília, v.23, n.84, p.99-122, nov. 2010.

VALVERDE BERROCOSO, J. V.; GARRIDO ARROYO, M. C. La función tutorial en entornos virtuales de aprendizaje: comunicación y comunidad. Revista

Latinoamericana de Tecnología Educativa, [S.1.], v.4, n.1, p.153-167, 2005. 